\title{
Analysis of the Three Most Prevalent Injuries in Australian Football Demonstrates a Season to Season Association Between Groin/Hip/ Osteitis Pubis Injuries With ACL Knee Injuries
}

\author{
Geoffrey M. Verrall ${ }^{1,2,}$; Adrian Esterman ${ }^{3}$; Timothy E. Hewett ${ }^{4}$ \\ ${ }^{1}$ South Australian Sports Institute, Adelaide, Australia \\ ${ }^{2}$ SPORTSMED.SA Sports Medicine Clinic, Adelaide, Australia \\ ${ }^{3}$ School of Nursery and Midwifery, University of South Australia, Adelaide, Australia \\ 4 Departments of Physiology and Cell Biology, Sports Health and Performance Institute, Ohio State University, Columbus, USA \\ *Corresponding author: Geoffrey M. Verrall, SPORTSMED.SA Sports Medicine Clinic, Adelaide, Australia. Tel: +61-883628111, Fax: +61-883626635, E-mail: verrallg@bigpond.com
}

Received: July 20, 2013; Accepted: February 10, 2014

\begin{abstract}
Background: Injuries are common in contact sports like Australian football. The Australian Football League (AFL) has developed an extensive injury surveillance database that can be used for epidemiological studies.

Objectives: The purpose of this study is to identify any association between the three most prevalent injuries in the AFL.

Patients and Methods: From the AFL injury surveillance data 1997-2012 the injury incidence (new injuries per club per season) and the injury prevalence data (missed games per club per season) were analysed to detect the three most common injuries that would cause a player to miss a match in the AFL. The three most prevalent injuries in the AFL are hamstring strains, groin/hip/osteitis pubis injuries and Anterior Cruciate Ligament (ACL) knee injuries. Following this, further study was undertaken to detect the presence of any statistical relationship between injury incidences of the three most prevalent injuries over this sixteen year study period.

Results: Statistical analysis demonstrates for any given year that there was an association between having a groin/hip/osteitis pubis injuriy and having a knee ACL injury $(\mathrm{P}<0.05)$ over the entire sixteen years. In other words if the number of groin/hip/osteitis pubis injuries in any given season were higher than average (alternatively lower) then the number of knee ACL injuries were also higher than average (alternatively lower) for that same season. Hamstring injuries had the highest variance of incidence of the three most prevalent injuries. Conclusions: Analysis of the AFL injury data demonstrates an association between incidence of groin/hip/osteitis pubis injuries and incidence of knee ACL injuries for any given playing season. This finding is difficult to explain with further research being required.
\end{abstract}

Keywords: Groin; Hip; Anterior Cruciate Ligament; Football; Groin; Muscles; Hip

\section{Background}

The various football codes played around the world, such as Australian football, have a high number of injuries, most often affecting the lower limb (1). Identifying risk factors for injuries in sport requires epidemiological studies looking at incidence and prevalence of injuries. One such epidemiological study looking at injuries in sport has been the Australian Football League (AFL) injury database (2). The AFL database has been fully compliant, meaning all (100\%) participants were identified and recorded in the database, and with a standard injury definition being "an injury or a medical condition which causes a player to miss a match" since 1997.

The AFL injury database over the 16 studied years has had consistent diagnostic categories. The injury report is an annual production available through the internet (3) and has been assessed as having sufficient scientific merit with peer review publication status (2). The principal injuries that afflict professional Australian football players over the sixteen year study period have been consistent; with hamstring injuries, groin/hip injuries and
Anterior Cruciate Ligament (ACL) knee injuries causing players to miss the most matches playing time, which are the highest prevalent injuries (3). Although consistent in their prevalence these injuries still have some season to season variability.

\section{Objectives}

Thus the purpose of this study was to analyses the database to detect whether the incidence (number of injuries causing players to miss a match) of the most prevalent injuries also had season to season variability and whether there was any association between these injuries on a season to season basis.

\section{Patients and Methods}

Permission was obtained from the AFL to analyses the data of this public document. Ethics approval as such was not required as it does not identify any specific person or relate to any specific intervention and the paper is retrospective in nature. The AFL injury surveillance data was

Copyright (C) 2014, Kowsar Corp.; Published by Kowsar. This is an open-access article distributed under the terms of the Creative Commons Attribution-NonCommercial 4.0 International License (http://creativecommons.org/licenses/by-nc/4.0/) which permits copy and redistribute the material just in noncommercial usages, provided the original work is properly cited. 
analysed from 1997-2012 (3). In the AFL database injuries were denoted when a player missed match playing time due to injury or a medical condition. Each player injury/ illness was diagnosed by the club doctor of the respective player and was categorized according to the AFL injury database diagnostic categories which are denoted using injury classification codes (3).

In the database injury incidence is measured in a unit of new injuries per club per season (where a club has 40 players and a season is 22 matches played weekly. The prevalence data is the amount of playing time missed through injury measured in a unit of missed games per club per season. The three most prevalent injuries in the AFL database (3) are hamstring strains (loss of 21 games per team per season on average over the study period of 16 years), groin strains/osteitis pubis/hip Injuries (16 games lost) and Anterior Cruciate Ligament (ACL) injuries of the knee (12 games lost). Overall prevalence with hamstring injuries (number one in all sixteen seasons), groin strains/osteitis pubis/hip injuries and ACL knee injuries (numbers two and three in all fifteen seasons except in 2010 where knee ACL was 4 th most prevalent behind shoulder strains). The incidence of these three most prevalent injuries is shown in Table 1.

The average incidences over the study period of 16 years were: hamstring, 6.1 new injuries per team per year; groin strains/osteitis pubis/hip injuries; 3.9 and ACL 0.7 (Table 1). There was no change in the injury definition of these three injuries over the study period and they are simply categorized as hamstring strains, groin strains/osteitis pubis/hip injuries and knee ACL injuries. Of interest is that the AFL injury database throughout the study period has always had separate categories for groin strains/osteitis pubis and hip injuries/groin injuries which for the purpose of this study have been combined.

From this we obtained three data sets (representing the three most prevalent injuries) of 16 variables (representing the incidence data of each year 1997-2012 of the injury surveillance). To detect the strength and direction of association between the variables (paired observations that are ranked) Spearman's Rho coefficient was calculated for the injury with highest prevalence compared with the injury with the second highest prevalence and the third highest prevalence separately. Additionally the coefficient was determined for the injury with the second highest prevalence with the injury with the third highest prevalence. The variance of the injuries was also calculated. Significance for association was determined to be $\mathrm{P}<0.05$.

\section{Results}

The variances of the three injuries were calculated as 0.59 hamstrings, 0.40 groins and 0.036 ACL. A graph depicting the incidence of the three major injuries, hamstring, groin strains/osteitis pubis and knee ACL, over the sixteen year period are shown in Figure 1 and Figure 2 . The statistical analysis is presented in Table 2 and dem- onstrates an association between having a groin strain/ osteitis pubis/hip injury and having a knee ACL injury ( $\mathrm{P}=$ 0.04 ) in any given season over the sixteen year study period. In other words when the number of groin strains/osteitis pubis/hip injuries in any given playing season was high then the number of knee ACL injuries was also likely to be high for that same playing season. Alternatively when the number of groin strains/osteitis pubis for any given year was low the number of knee ACL injuries was also likely to be low for that same year. Although there was no association demonstrated for having a hamstring strain and groin strain/osteitis pubis/hip injuries there was a reasonably strong correlation of $0.435(\mathrm{P}=0.1)(\mathrm{Ta}-$ ble 2) but none for having a hamstrings strain with a knee ACL injury over the sixteen year study period.

Table 1. Incidence (Number of New Injuries Per Club Per Season) for the Three Most Prevalent (Number of Missed Games Per Playing Season) Injuries Over the Last 16 Playing Seasons

\begin{tabular}{lccc}
\hline Year & Hamstring Groin Strains/Osteits Pubis/Hip & ACL \\
Injuries
\end{tabular}

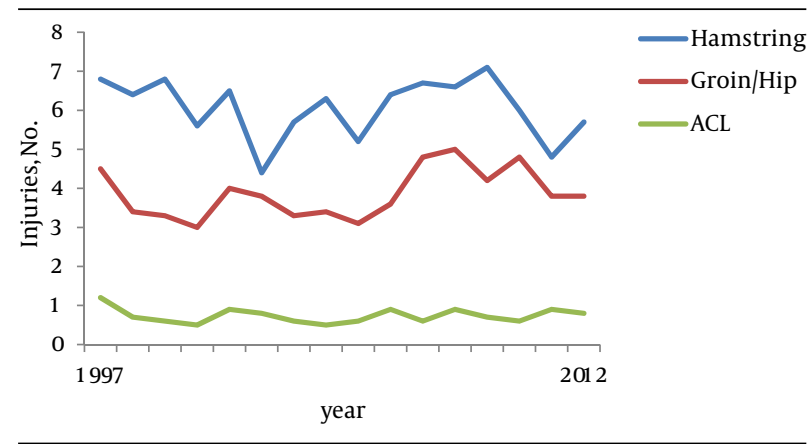

Figure 1. Incidence of the Three Most Common AFL Injuries (From the AFL Injury Database) With Number of Injuries on Y Axis and Years 1997-2012 on the X Axis 
Verrall GM et al.

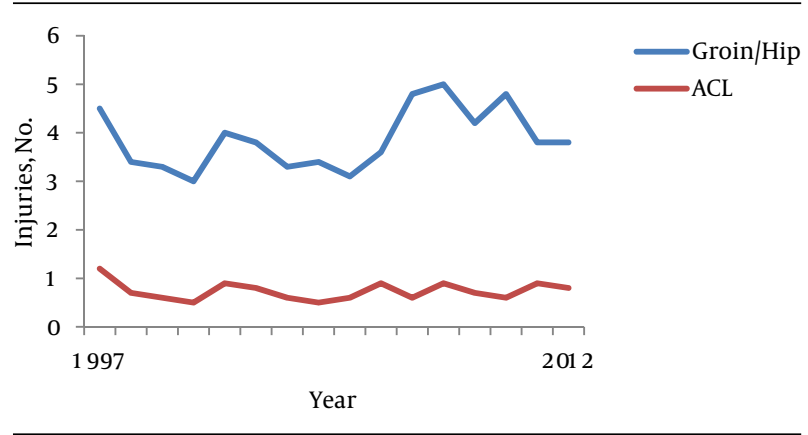

Figure 2. Incidence of Groin Strains/Osteitis Pubis With ACL Injuries Depicting Similar Shaped Curves (From the AFL Injury Database) Number of Injuries on Y Axis and Years 1997-2012 on the X Axis

Table 2. Correlation Between Hamstring, Groin/Hip/Osteitis Pubis Injuries and Knee ACL Injuries Over 16 Years in the AFL

\begin{tabular}{lccc}
\hline Spearman's Rho & $\begin{array}{c}\text { Groin/Hip/Os- } \\
\text { teitis Pubis }\end{array}$ & Hamstring & Knee ACL \\
\hline Hamstring & & & \\
\hline $\begin{array}{l}\text { Correlation coef- } \\
\text { ficient }\end{array}$ & 0.435 & 1.000 & 0.181 \\
\hline $\begin{array}{l}\text { PValue (2 tailed) } \\
\text { Groin/hip/osteitis } \\
\text { pubis }\end{array}$ & 0.1 & & 0.5 \\
$\begin{array}{l}\text { Correlation coef- } \\
\text { ficient }\end{array}$ & 1.000 & 0.453 & 0.515 \\
$\begin{array}{l}\text { PValue (2 tailed) } \\
\text { Knee ACL }\end{array}$ & - & 0.1 & 0.04 \\
$\begin{array}{l}\text { Correlation coef- } \\
\text { ficient }\end{array}$ & 0.515 & 0.181 & 1.000 \\
\hline \begin{tabular}{l} 
PValue (2 tailed) \\
\hline
\end{tabular} & 0.04 & 0.5 & - \\
\hline
\end{tabular}

\section{Discussion}

The principal finding of this study was the association demonstrated between the incidences of groin strains/ osteitis pubis/hip injuries with knee ACL injuries in any given playing season. That such an association was demonstrated over a considerable length of time (sixteen seasons) combined with the large size and highly reliable, in terms of data collection, AFL injury database give credence that the connection between these two injuries is not an incidental finding. A simple explanation for this finding would be that athletes in one season who miss a game for groin strain/osteitis pubis/hip injuries would also miss a game for a knee ACL injury. This is considered most unlikely as knee ACL injury results, in Australian football, in the athlete having an ACL knee reconstruction and return to sport in that same playing season generally does not occur (4). Also ACL injuries in Australian football have an early in the playing season predominance (4). Therefore, this simple explanation of the same players having the same injury in the same season seems unlikely, though cannot be ruled out by the nature of this particular study. Thus a direct causal relationship is unlikely so the most likely explanation is a confounder (a common risk factor) to both groin injuries and knee ACL injuries.

No association has been demonstrated, or noticed, previously including in studies on knee ACL injuries and groin strains/osteitis pubis/hip injuries in Australian football. One previous prospective study of Australian football players demonstrated that having a previous groin strain/osteitis pubis or having a previous significant knee injury was a risk factor for a subsequent hamstring injury (5), but no association between having a groin strain/osteitis pubis/hip injury with a knee ACL injury has, to our knowledge, been established. Over the 16 years of the study period there is evidence that game speed in the AFL has increased and is continuing to increase (6). Therefore increasing game speed does not appear to be associated with a fluctuating incidence of groin strains/osteitis pubis/hip injuries and knee ACL injuries. From here any attempt to explain this finding of an association between having a groin strain/osteitis pubis and knee ACL in Australian football can only be considered speculative and unsubstantiated.

Alternative explanations that have been considered by the authors include ground conditions or the training programs associated with preparing for and playing Australian football. In other words the ground conditions and or training programs used either collectively increase the incidence of $\mathrm{ACL} /$ groin strain/osteitis pubis/ hip injuries or alternatively are collectively protective (relative to other seasons) of ACL/groin strain/osteitis pubis injuries. The ground condition potentially either causing an increase in the incidence of ACL and groin injuries, or decreasing the incidence, is unable to be scientifically tested. All states of Australia have grounds that are used to play AFL matches. It has been demonstrated in the past that certain types of grasses are associated with non-contact ACL injuries in Australian football (7). There was a proposed project to assess ground hardness at all Australian football venues (8), but this project was abandoned so no information on the hardness, or softness, of the AFL grounds has been kept in the 16 year study period. To explain the findings of this study would rely on the fact that the ground conditions over a continent as large as Australia (matches are played in the most Northern, Southern, Eastern and Western part of the country) would rise and fall identically with the rise and fall of knee ACL and groin/hip injuries. A similar explanation would be required for weather patterns such as rainfall. These are unable to be properly tested at this time.

An alternative hypothesis for the principal finding demonstrated by this study is the training programs that are undertaken by the AFL football clubs in preparing for the football playing season. As stated in the AFL there is a higher incidence of knee ACL injuries in the early part of the playing season (4) suggesting that, amongst other factors, the pre-season training period is important. This 
hypothesis relies on the premise that from season to season there is a degree of homogeny between all of the AFL football clubs with respect to fitness/conditioning programs. This homogeny also extends to the response of the AFL clubs to the incidence of injuries in any given season and again is highly speculative. Due to the low incidence of ACL injuries and their lack of season to season variability, even though there is high prevalence, there is little effort put into prevention programs by the football clubs for this particular injury that is generally considered to affect random players from random clubs. In contrast to ACL injuries, groin/hip injuries are far more problematic, with players missing a game through injury being unlikely to be the full extent of the groin/hip problem at any particular club. The reason for this is that there are many groin injuries that do not miss playing time (9) these are not represented in the AFL data. As a consequence, with a higher prevalence and a higher incidence of groin injuries compared to knee ACL injuries there is more likelihood that groin injuries are targeted for prevention considerations when designing and undertaking pre-season fitness/conditioning programs. Hence if the number of groin injuries for any given season across the entire league is high then it is likely a collective effort, without this being a coordinated approach, to prevent these groin injuries for the subsequent season from occurring. Alternatively if the number of groin injuries for a given season is low then there is likely to be less impetus to carry on with or establish groin injury prevention programs. What is surprising about all this is how the numbers of knee ACL injuries is also affected in a similar, almost exactly, same manner.

Current considerations of the reasons for ACL injuries include the athletes can be ligament dominant, quadriceps dominant, side dominant and trunk dominant (10). The power of turning/twisting is likely to be, in part, the function of the quadriceps muscle. With respect to ligament dominance and side dominance, in the AFL ACL injuries do not demonstrate dominant side predilection (4), these are unlikely factors in considering combined ACL and groin injury risks. With respect to trunk dominance this often refers to the fact that females have a higher center of gravity mass resulting in a higher risk for injury. It is very difficult to measure and for the purposes of this paper is not considered a likely cause of the combined risk of ACL and groin injuries. It is also unlikely to be changed as a consequence of any intervention program.

Any pre-season program that may emphasize quadriceps dominance, wittingly or unwittingly, could in theory increase ACL and groin injury risk. Quadriceps dominance in the terms of knee mechanics determines the power and speed of any anterior-posterior translation of knee thus without being balanced by hamstrings can increase ACL injury risk upon turning. With respect to prevention of knee ligament injuries, in other words to decrease the tendency towards quadriceps dominance, exercises are employed which emphasize co-contraction of the knee flexor/extensor muscles (11). In a similar manner quadriceps dominance can increase the power and speed of a turn/twist and as judged by the epidemiology of the types of athletes who contract groin injuries, being predominately found in sports where twisting and turning are common (12-15), could increase the risk for groin injuries.

A recent demonstrated risk factor for a groin injury has been decreased hip joint range of motion, in particular a restriction of hip internal rotation(16). It is proposed that a loss of hip internal rotation places an added stress upon the pelvic ring when the athlete undertakes turning and twisting thus leading to an increased risk for groin injury (16). Interestingly, at the knee joint, increased tibial internal rotation is considered to be a risk factor for ACL injuries (17). It is known that internal hip range of motion loss is greater in the Australian football population when compared to normal (18). Hence if the hypothesis that loss of hip range of motion can lead to excessive pelvic stress is true then it is also feasible that the knee too undergoes additional stressors to compensate for the biomechanical change. These changes in biomechanical stresses may also be influenced by player conditions such as fatigue (19).

It must be stated that very little information exists about groin/hip injury prevention programs in Australian football, nor for that matter in any other sport (20). Components of such programs include core stability strengthening and activation programs, strengthening of pelvic stabilizing muscles such as the gluteal and adductors, flexibility improvements of the major agonist and antagonist movement muscles, changes in the running/training program (generally a change in the aerobic/anaerobic running mix), and athletic load management/recovery methods. So it is possible that changing these components in the preseason training program results in changing the incidence of groin injuries in a similar manner to changing the incidence of ACL injuries.

If the principal reason for the link from season to season between groin injuries and ACL injuries is the nature of the pre-season training program, then from the results of this study this is not the principal determinant of variation in the number of hamstring injuries. Hamstring injuries had the highest variance of the three injuries analysed in this study. As hamstring injuries are generally of sudden onset and predominately occur in match playing situations (21), it is possible that game factors, such as the number of player interchanges and player fatigue (22), and player intrinsic factors, such as previous hamstring injury $(5,23,24)$ and age of players $(5,23,25)$, have a more predominant role in determining the variation in these injuries. This study has a significant number of weaknesses partly no doubt due to the nature of the speculative nature of explaining the principal findings of this study. With respect to methodology the AFL injury data does not give specific information about who the 
Verrall GM et al.

injury affects, no information about any particular club or region being more affected. In the statistical analysis although the study is over 16 years the associations are collected over only 16 different observations. This is a significant limitation of the study. Finally the methodology of this study is unusual in the field of sports medicine/ injuries. In effect we have analysed another study looking for associations. This type of study is more common in the analysis of cancer registries and in more recent time joint replacement registries.

A strong association exists between incidence of groin strains/osteitis pubis/hip injuries and ACL knee injuries in the Australian Football League (AFL). Thus an increase and decrease in incidence between these two injuries paralleled each other over the 16 year study period. The reasons for this at this time are unknown. Hamstring injuries demonstrate the highest variance in the most prevalent AFL injuries. At this time a single predominant cause of this variation is not possible to be deduced.

\section{Acknowledgements}

The authors would like to acknowledge the AFL and the AFLMOA (AFL Medical Officers Association) for their support in analyzing the AFL injury surveillance data.

\section{Authors' Contributions}

All authors were involved in analyzing the data and subsequent production of the manuscript.

\section{Funding/Support}

This research received no specific grant from any funding agency in the public, commercial or not-for-profit sectors. Permission for this study was obtained from the AFL.

\section{References}

1. Seward H, Orchard J, Hazard H, Collinson D. Football injuries in Australia at the elite level. Med J Aust.1993;159(5):298-301.

2. Orchard JW, Seward H, Orchard JJ. Results of 2 decades of injury surveillance and public release of data in the Australian Football League. Am J Sports Med. 2013;41(4):734-41.

3. Orchard J, Seward H. 2012 AFL Injury Report.; 2013.

4. Orchard J, Seward H, McGivern J, Hood S. Intrinsic and extrinsic risk factors for anterior cruciate ligament injury in Australian footballers. Am J Sports Med. 2001;29(2):196-200.

5. Verrall GM, Slavotinek JP, Barnes PG, Fon GT, Spriggins AJ. Clinical risk factors for hamstring muscle strain injury: a prospective study with correlation of injury by magnetic resonance imaging. Br J Sports Med. 2001;35(6):435-9.

6. Gray AJ, Jenkins DG. Match analysis and the physiological de- mands of Australian football. Sports Med. 2010;40(4):347-60.

7. Orchard JW, Chivers I, Aldous D, Bennell K, Seward H. Rye grass is associated with fewer non-contact anterior cruciate ligament injuries than bermuda grass. Br J Sports Med. 2005;39(10):704-9.

8. Orchard J. The AFL penetrometer study: work in progress. $J$ Sci Med Sport. 2001;4(2):220-32.

9. Verrall GM, Slavotinek JP, Fon GT. Incidence of pubic bone marrow oedema in Australian rules football players: relation to groin pain. BrJ Sports Med. 20 01;35(1):28-33.

10. Hewett TE, Ford KR, Hoogenboom BJ, Myer GD. Understanding and preventing acl injuries: current biomechanical and epidemiologic considerations - update 2010. N Am J Sports Phys Ther. 2010;5(4):234-51.

11. Fitzgerald GK, Axe MJ, Snyder-Mackler L. The efficacy of perturbation training in nonoperative anterior cruciate ligament rehabilitation programs for physical active individuals. Phys Ther. 2000;80(2):128-40.

12. Ekberg O, Persson NH, Abrahamsson PA, Westlin NE, Lilja B. Longstanding groin pain in athletes. A multidisciplinary approach. Sports Med.1988;6(1):56-61.

13. Engebretsen AH, Myklebust G, Holme I, Engebretsen L, Bahr R. Intrinsic risk factors for groin injuries among male soccer players: a prospective cohort study. Am J Sports Med. 2010;38(10):2051-7.

14. Fricker PA, Taunton JE, Ammann W. Osteitis pubis in athletes. Infection, inflammation or injury? Sports Med.1991;12(4):266-79.

15. Lovell G. The diagnosis of chronic groin pain in athletes: a review of 189 cases. Aust J Sci Med Sport. 1995;27(3):76-9.

16. Verrall GM, Slavotinek JP, Barnes PG, Esterman A, Oakeshott RD, Spriggins AJ. Hip joint range of motion restriction precedes athletic chronic groin injury. J Sci Med Sport. 2007;10(6):463-6.

17. Branch TP, Browne JE, Campbell JD, Siebold R, Freedberg HI, Arendt EA, et al. Rotational laxity greater in patients with contralateral anterior cruciate ligament injury than healthy volunteers. Knee Surg Sports Traumatol Arthrosc. 2010;18(10):1379-84.

18. Verrall GM, Hamilton IA, Slavotinek JP, Oakeshott RD, Sprig gins AJ, Barnes PG, et al. Hip joint range of motion reduction in sports-related chronic groin injury diagnosed as pubic bone stress injury.J Sci Med Sport. 2005;8(1):77-84.

19. Thomas AC, McLean SG, Palmieri-Smith RM. Quadriceps and hamstrings fatigue alters hip and knee mechanics. J Appl Biomech. 2010;26(2):159-70.

20. Maffey L, Emery C. What are the risk factors for groin strain injury in sport? A systematic review of the literature. Sports Med. 2007;37(10):881-94.

21. Verrall GM, Slavotinek JP, Barnes PG, Fon GT. Diagnostic and prognostic value of clinical findings in 83 athletes with posterior thigh injury: comparison of clinical findings with magnetic resonance imaging documentation of hamstring muscle strain. Am J Sports Med. 2003;31(6):969-73.

22. Orchard JW, Driscoll T, Seward H, Orchard JJ. Relationship between interchange usage and risk of hamstring injuries in the Australian Football League. J Sci Med Sport. 2012;15(3):201-6.

23. Engebretsen AH, Myklebust G, Holme I, Engebretsen L, Bahr R. Intrinsic risk factors for hamstring injuries among male soccer players: a prospective cohort study. Am J Sports Med. 2010;38(6):1147-53.

24. Orchard JW. Intrinsic and extrinsic risk factors for muscle strains in Australian football. Am J Sports Med. 2001;29(3):300-3.

25. Gabbe BJ, Bennell KL, Finch CF. Why are older Australian football players at greater risk of hamstring injury? J Sci Med Sport. 2006;9(4):327-33. 